\section{Sanding and Pruning Differentially Impact Canopy Characteristics, Yield, and Economic Returns in Cranberry}

\author{
Brett Suhayda ${ }^{1}$, Carolyn J. DeMoranville ${ }^{1,4}$, Hilary A. Sandler ${ }^{1}$, \\ Wesley R. Autio ${ }^{2}$, and Justine E. Vanden Heuvel $^{3}$
}

AdDITIONAL INDEX wORDs. Vaccinium macrocarpon, anthocyanin, light penetration, leaf wetness

SUMMARY. Sanding and pruning are two practices used in the cranberry (Vaccinium macrocarpon) industry for vine management and yield stimulation. This study compared varying levels of sanding and pruning on vine canopy characteristics, yield, and economic returns for two consecutive growing seasons. Each practice was applied in Apr. 2006 at four levels. Sand was applied directly onto the vines at four depths: control $(0 \mathrm{~cm})$, light $(1.5 \mathrm{~cm})$, moderate $(3.0 \mathrm{~cm})$, or heavy $(4.5 \mathrm{~cm})$; pruning was conducted at four severities with a commercial pruner: control (not pruned), light (one pass with the pruner), moderate (two passes), and heavy (three passes). Pruning levels had no effect on upright density over the two seasons, but the heavy sanding treatment decreased the number of uprights per unit area. For the first season only, light penetration to soil level increased linearly as severity increased for pruning and sanding. The number of reproductive uprights relative to total uprights decreased in the first year as severity increased for both practices. This effect continued in the second year for sanding treatments. Cumulative yield and net returns were higher in light severity treatments compared to those in the moderate and heavy treatments. Moderate and heavy sanding treatments were associated with lower yields and net returns than those for the untreated controls.

$\mathrm{C}$ ranberry is a low-growing vine, with a perennial growth habit (Eck, 1990). Native to North America, cranberry reproduces vegetatively by horizontal shoots (stolons), known in the cranberry industry as runners, or by shorter vertical shoots, known as uprights, produced from axillary buds (Roper and Vorsa, 1997). Individual uprights bear fruit in a biennial manner (Roper et al., 1993). After several years, uprights eventually bow under their own weight and function as runners (Eck, 1990).

Excessive vegetative growth in cranberry can be detrimental to yield

This work was supported by Northeast Region SARE Project LNE05-217 and is a portion of a Masters thesis from the University of Massachusetts-Amherst, Department of Plant, Soil, and Insect Sciences submitted by B. Suhayda.

Special thanks to Peter Jeranyama for statistical assistance and to Joe DeVerna and Duane Greene for comments on the manuscript.

${ }^{1}$ University of Massachusetts Amherst Cranberry Station, P.O. Box 569, East Wareham, MA 02538

${ }^{2}$ Department of Plant, Soil, and Insect Sciences, University of Massachusetts Amherst, Amherst, MA 01003

${ }^{3}$ Department of Horticultural Sciences, Cornell University, Geneva, NY 14456

${ }^{4}$ Corresponding author. E-mail: carolynd@umext. umass.edu.
(Davenport and Vorsa, 1999) as a result of shading or fungal disease. Shading has been shown to have a significant negative impact on cranberry fruit set (Roper et al., 1995), and flower bud formation depends on adequate light penetration (Roper et al., 1993). In addition to shading, excessive vegetative growth may increase the relative humidity under the canopy, resulting in a microenvironment conducive to fruit rot and other fungal diseases (Oudemans et al., 1998).

As with flower bud formation, fruit anthocyanin production depends on adequate light penetration
(Strik and Poole, 1991; Toledo et al., 1993). The cranberry fruit must exceed a minimum anthocyanin content to be accepted for sale as processed fruit; extra compensation may be awarded to growers for fruit with high anthocyanin content. Due to the potentially detrimental effects of excessive vegetation, it is important to employ cultural practices that maintain good canopy architecture.

Sanding is a cultural practice used in the northeastern United States and Wisconsin to manage the cranberry plant canopy. Typically, this practice is performed every 2 to 5 years with a 0.5 - to 2 -inch layer of sand spread over an ice-covered bed during the winter (DeMoranville and Sandler, 2000). The sand is allowed to melt through the ice to ultimately settle on the cranberry vines so that runners are buried and rooting is encouraged. This stimulates the growth of new uprights that may bear fruit the following year (DeMoranville and Sandler, 2000). Previous studies of sanding have shown mixed results regarding potential effects on crop yield. Strik and Poole (1995) found that heavy sanding $(2.5 \mathrm{~cm})$ on two 'Stevens' beds in Oregon was detrimental to yield, while light sanding $(1.3 \mathrm{~cm})$ improved yield in the year after treatment at only one of the two sites. Davenport and Schiffhauer (2000) also showed that heavy sanding was detrimental. In Massachusetts, sanding decreased the percentage of light intercepted by uprights and runners and was associated with yield decreases (Lampinen and DeMoranville, 2003).

Pruning is another method that can be used for canopy management. Much like sanding, pruning opens the canopy and encourages new growth

\begin{tabular}{llll}
\hline $\begin{array}{l}\text { Units } \\
\begin{array}{l}\text { To convert U.S. to SI, } \\
\text { multiply by }\end{array}\end{array}$ & U.S. unit & SI unit & $\begin{array}{l}\text { To convert SI to U.S., } \\
\text { multiply by }\end{array}$ \\
\hline 0.4047 & $\mathrm{acre}(\mathrm{s})$ & $\mathrm{ha}$ & 2.4711 \\
0.3048 & $\mathrm{ft}$ & $\mathrm{m}$ & 3.2808 \\
0.0929 & $\mathrm{ft}^{2}$ & $\mathrm{~m}^{2}$ & 10.7639 \\
2.54 & inch $(\mathrm{es})^{2}$ & $\mathrm{~cm}^{2}$ & 0.3937 \\
6.4516 & inch $^{2}$ & $\mathrm{~cm}^{2}$ & 0.1550 \\
645.1600 & inch $^{2}$ & $\mathrm{~mm}^{2}$ & 0.0016 \\
0.4536 & $\mathrm{lb}$ & $\mathrm{kg}$ & 2.2046 \\
1.1209 & $\mathrm{lb} / \mathrm{acre}^{2}$ & $\mathrm{~kg} \cdot \mathrm{ha}^{-1}$ & 0.8922 \\
28.3495 & $\mathrm{Oz}$ & $\mathrm{g}$ & 0.0353 \\
305.1517 & $\mathrm{Oz} / \mathrm{ft}^{2}$ & $\mathrm{~g} \cdot \mathrm{m}^{-2}$ & 0.0033 \\
0.7646 & $\mathrm{yard}$ & $\mathrm{m}^{3}$ & 1.3080 \\
$\left({ }^{\circ} \mathrm{F}-32\right) \div 1.8$ & ${ }^{\circ} \mathrm{F}$ & ${ }^{\circ} \mathrm{C}$ & $\left(1.8 \times{ }^{\circ} \mathrm{C}\right)+32$
\end{tabular}


(Marucci, 1987), and has the potential benefit of breaking apical dominance, allowing lateral buds to grow (Roper et al., 1993). More uprights are produced that have the potential of fruiting the following year. Chambers (1918) performed pruning experiments on a heavily vined bed that had been steadily declining in production and reported a $10 \%$ decrease in yield in the initial year followed by a $45 \%$ increase in the following year. Strik and Poole $(1991,1992)$ also reported reduced yield from heavy pruning in the years of treatment but that light pruning yielded more fruit compared with the control in the following year.

While sanding and pruning have shown the potential to be beneficial, sanding has some shortcomings when compared with pruning. In addition to the high costs associated with the use of a limited resource, measurements of actual sand depths from three methods of sand application on 24 Massachusetts farms indicated a lack of uniform deposition (Hunsberger et al., 2006), which may diminish desired outcomes (e.g., uniform upright generation and pest management). Because pruning appears to accomplish the same horticultural goals as sanding with better uniformity and lower costs, it has been suggested as a replacement or supplement to sanding. However, these two practices have not been compared directly within the same cranberry bed. The objective of this study was to compare pruning and sanding treatments on 'Stevens' cranberry to determine effects on crop yield, economic returns, canopy characteristics, and fruit color.

\section{Materials and methods}

EXPERIMENTAL DESIGN. A mature 'Stevens' cranberry bed in Myles Standish State Forest, North Carver, MA (lat. $41^{\circ} 53^{\prime} 09.74^{\prime \prime} \mathrm{N}$, long. $\left.70^{\circ} 41^{\prime} 55.23^{\prime \prime} \mathrm{W}\right)$ was used for this experiment. The bed was renovated in 2000 and was never pruned before the study. An application of 0.5 inch of sand was made to the entire bed in Apr. 2002. Applications of fertilizers each year were made to the entire bed, including the study area, based on standard nutrition recommendations (DeMoranville, 2009).

The study was established in 2006 as a randomized complete block design arranged in a split-plot with the main effect of sanding or pruning and the subplot was severity level. All treatments were replicated four times. The sanding treatments were applied on 14 Apr. 2006 using coarse sand, mined on-site. A commercial sander (a small self-propelled vehicle with a hopper and a drop spreader) was used for on-vine sanding. The sander was calibrated to deliver a depth of $1.5 \mathrm{~cm}$ sand on each pass. The levels of sanding were determined by the number of times the sander passed over the plot: control (0 passes), light (one pass), moderate (two passes), and heavy (three passes). Each sanding plot was $8 \mathrm{ft}$ (the width of the sander) $x$ $25 \mathrm{ft}$.

The pruning treatments were applied on 17 Apr. 2006 using a commercial pruner (a small, self-propelled, mechanical knife-rake pruner with revolving blades). A rake mounted on the back of the pruner collected the prunings. As with the sanding, the levels of pruning were determined by the number of times the pruner passed over the plots: control ( 0 passes $)$, light (one pass), moderate (two passes), and heavy (three passes). Each pruning plot was $6 \mathrm{ft}$ (the width of the machine) $\times 25 \mathrm{ft}$. Fresh weights of vines excised during the pruning process were collected and weighed in the field.

UPRIGHT DENSITY, LEAF AREA, AND DRY WEIGHT. A 6-inch-diameter ring $\left(28\right.$ inch $\left.^{2}\right)$ was placed randomly in each plot on 2 June 2006 and again on 4 June 2007. All plant material originating from within the ring was removed. This sampling was repeated twice in each plot. The excised plant material from each ring was evaluated as follows. The uprights were removed at the origin and were counted to determine density. The leaves were removed, and leaf area was measured using a leaf area meter (model LI3100; LI-COR, Lincoln, NE). All of the collected plant material was dried at $70^{\circ} \mathrm{C}$ for $10 \mathrm{~d}$ and weighed.

FrUITING UPRIGHTS $\left(\mathrm{U}_{\mathrm{F}}\right)$ /TOTAL UPRIGHT $\left(U_{T}\right)$ RATIO. Once each year in late summer, random samples of $\approx 25$ uprights were collected from each plot, counted, and evaluated as fruiting (presence of fruit or persistent pedicels) or nonfruiting. The ratio of $\mathrm{U}_{\mathrm{f}}: \mathrm{U}_{\mathrm{t}}$ was then calculated.

Light PENETRATION. Light penetration into the cranberry canopy was measured in the second week of
July and the third week of August in both 2006 and 2007 using an Accupar linear PAR/LAI ceptometer (model PAR-80; Decagon Devices, Pullman, WA). An external, unobstructed sensor was also employed to determine the ratio of below-canopy light to above-canopy light (tau). The ceptometer was placed under the canopy in a south-west direction at four randomly selected locations in each plot; hence, 32 readings were taken in each block. Readings were converted to percentage of light penetration by multiplying tau by 100 . In both years, readings were only taken from blocks 1 and 2 due to weather and time restrictions.

LEAF WETNESS. Leaf wetness was recorded at 0.5 -h intervals using micro-dataloggers and leaf wetness sensors (Hobo microstation data loggers and leaf wetness smart sensors; Onset Computers, Bourne, MA). Based on field observations, the dry/wet threshold was set at $20 \%$ to control for error in the sensor readings. Data were collected for 4 weeks in each year by deploying eight logger/sensor pairs each time. Block 1 was monitored in the first week of July 2006; the eight logger/sensor pairs were relocated to block 2 during the second week of July 2006. Using these data, the average of number of dry hours per week in early July was determined. Sensors were redeployed similarly in the third and fourth weeks of August, and the average number of dry hours per week in late August was calculated. The procedure was repeated in 2007.

Penetration of chemigation INTO THE CANOPY. Water-sensitive papers (TeeJet, Wheaton, IL) were used to measure spray penetration through the canopy. The papers change color (from yellow to blue) when water contacts the papers. Attached to a stake, papers were placed at the base of the canopy and midway between the base and tips of the uprights. Irrigation was applied through a solid-set sprinkler system for $15 \mathrm{~min}$, simulating a typical chemigation event for a pesticide application. The papers were allowed to dry, and were then collected and brought back to the laboratory for evaluation. Penetration was visually evaluated using a grid system and a scale of $0=$ no penetration (all yellow) to $100=$ total penetration (all blue). 
BERRY YIELD AND MARKETABLE YIELD. In 2006 and 2007, berry yield was estimated using a $1-\mathrm{ft}^{2}$ template randomly placed within each plot. All berries were picked from within the $1-\mathrm{ft}^{2}$ area, and all viable berries were weighed. Two subsamples were taken from each plot, and the data from the subsamples were averaged. Average berry weight was also determined using subsamples from each plot. In 2007, nonmarketable berries (i.e., berries deemed too small, rotten, or insect-damaged) were counted to calculate marketability percentage.

TOTAL ANTHOCYANIN CONCENTRATION (TACY). Additional fruit were collected randomly (outside the area sampled for yield) at harvest for TAcy determination. Total anthocyanin concentration (milligrams per $100 \mathrm{~g}$ of fresh weight) in harvested cranberry fruit samples was determined with a modification of the protocol of Fuleki and Francis (1968) using an acidified aqueous extractant (0.2 $\mathrm{N}$ hydrochloric acid).

Economic analysis. The cost of treatments, including equipment and labor costs on a per acre basis, were assigned based on information provided by two commercial cranberry growers (R. Gilmore and M. Beaton, personal communication). The costs for light pruning included the pruning machine $(\$ 40 / \mathrm{h})$, the buggy to remove cut vines $(\$ 40 / \mathrm{h})$, one equipment operator $(\$ 75 / \mathrm{h})$, and five laborers ( $\$ 14 / \mathrm{h}$ each). The total cost for $8 \mathrm{~h}$ (time to prune 10 acres) was $\$ 1800$ or $\$ 180$ per acre. Costs for the moderate and heavy pruning treatments were calculated by doubling or tripling, respectively, the cost of the light severity treatment as more severe pruning required multiple passes with the pruner.

The costs for the light sanding treatment included one front end loader $(\$ 60 / \mathrm{h})$, three sanders (\$27.50/h each), four skilled laborers $(\$ 30.50 / \mathrm{h}$ each), and a daily move-in charge for the equipment of $\$ 150$. The total cost for an 8 -h day (time to sand 7 acres at light severity) was $\$ 2388$ or $\$ 341 /$ acre for machines and labor. To define a multiplier for the moderate and heavy treatments, it was recognized that fewer acres would be sanded on a daily basis compared with the light treatment and costs would be higher due to longer equipment rental and labor expenditures. Based on grower experience, costs for the moderate and heavy sanding treatments were calculated by multiplying the cost of the light sanding by 1.5 and two, respectively. To these costs was added the cost of sand, $\$ 12 /$ yard $^{3}$ screened and delivered (Cape Cod Cranberry Growers Assn., East Wareham, MA) so that the total costs per acre for the sanding treatments were \$1291, $\$ 2415$, and $\$ 3536$ for light, moderate, and heavy severities, respectively. Purchased sand was used in this calculation because not all growers have access to on-farm sand.

The average total cost of production for beds that were not sanded or pruned was $\$ 3200 /$ acre in 2006 and $\$ 3300$ /acre in 2007 (G. Rogers, personal communication). The price of cranberries used for the analysis ( $\$ 38.80$ and $\$ 43.40$ per 100 -lb barrel in 2006 and 2007, respectively) was the blended return for fresh and processed fruit to growers in Massachusetts (U.S. Department of Agriculture, 2008).

DATA ANAlysis. Analyses of variance were conducted on all data using the Proc GLM procedure in SAS (version 9.1; SAS Institute, Cary, NC). Model assumptions were tested through residual analysis (ShaprioWilk statistic), and no transformations were needed. Although pruning and sanding severity is referred to in the text with the labels of light, moderate, and heavy, treatment levels were analyzed as continuous variables to reflect the continuity of treatment application (e.g., sequential number of passes) with which the vines were sanded or pruned. Responses to pruning or sanding severity were determined by evaluating linear and quadratic trends from single df analysis.

\section{Results and discussion}

CANOPY CHARACTERISTICS. Pruning weights collected from the spring pruning event in 2006 were nonlinear with respect to severity (light $=394 \pm 149 \mathrm{lb} /$ acre, moderate $=376 \pm 173 \mathrm{lb} /$ acre , and heavy $=580$ $\pm 210 \mathrm{lb} /$ acre $)$. When the study was established in 2006, the vines had not formed a continuous vigorous canopy (desired end goal); this may have been due to the age of the bed combined with certain negative environmental factors (e.g., high soil moisture conditions). In a previous study on a vigorous uniform 'Stevens' canopy, multiple-pass pruning did produce a linear response in pruning weights removed (Sandler and DeMoranville, 2009). The irregularity of the vine coverage in the present study bed may account for lack of differences noted in some responses for the levels of pruning.

In the year of treatment and the year following, upright density was unaffected by pruning, but decreased quadratically with increasing sanding severity (Table 1). In 2007, the total number of uprights for all treatments (including the control) increased compared with 2006. The lack of a pruning effect is consistent with the results of Strik and Poole (1991, 1992) who reported no significant effect of pruning on total number of uprights in the year of treatment or the year after. The difference between sanding and pruning effects on upright density was likely the result of the heavy sanding treatments burying young uprights. Although the difference was not significant, a slight increase in upright density the year after treatment in the light sanding and pruning treatments compared with the control may indicate a stimulation of upright initiation from axillary buds.

Total dry weight per sampled area decreased linearly with increasing sanding severity in the year of treatment, while pruning displayed a quadratic relationship with lowest dry weight for the control and the heavy treatment (Table 1 ). Treatment differences were not significant in the year after treatment.

In the first year, total leaf area displayed a quadratic relationship with increasing severity for both treatments (Fig. 1A). Both light severity treatments had a slight stimulatory effect on leaf area, whereas the heavy treatments (sanding in particular) were associated with decreased leaf area. This trend continued in the second year for sanding only (Fig. 1B). When leaf area was expressed on a per upright basis, the response was a negative linear relationship in the first year with increasing sanding severity, but the relationship was nonsignificant with pruning (Fig. 1C). There were no significant relationships in the year following treatment (Fig. 1D). These data indicated that the predominant impact of both sanding and pruning 
Table 1. Effect of pruning and sanding severity on various cranberry vine parameters. Treatments were applied in Apr. 2006. Sanding and pruning treatments were achieved by making one, two, or three passes per plot.

\begin{tabular}{|c|c|c|c|c|c|c|c|c|c|}
\hline \multirow[b]{2}{*}{ Treatment } & \multirow[b]{2}{*}{ Severity } & \multicolumn{2}{|c|}{$\begin{array}{c}\text { Uprights } \\
\left(\text { no. } / \mathrm{ft}^{2}\right)^{\mathrm{z}}\end{array}$} & \multicolumn{2}{|c|}{$\begin{array}{c}\text { Total dry wt } \\
\left(\mathrm{g} / \mathrm{ft}^{2}\right)^{\mathrm{z}}\end{array}$} & \multicolumn{2}{|c|}{$\begin{array}{c}\text { Light penetration } \\
(\text { tau })^{\mathrm{y}}\end{array}$} & \multicolumn{2}{|c|}{$\begin{array}{r}\mathrm{U}_{\mathrm{f}} / \mathrm{U}_{\mathrm{t}} \\
(\text { ratio })^{\mathrm{x}} \\
\end{array}$} \\
\hline & & 2006 & 2007 & 2006 & 2007 & July 06 & Aug. 06 & 2006 & 2007 \\
\hline \multirow{4}{*}{ Pruning } & Control & 324 & 459 & 58.1 & 74.1 & 0.09 & 0.07 & 0.40 & 0.36 \\
\hline & Light & 355 & 534 & 73.6 & 90.5 & 0.10 & 0.12 & 0.39 & 0.40 \\
\hline & Moderate & 424 & 486 & 74.1 & 84.9 & 0.25 & 0.11 & 0.30 & 0.40 \\
\hline & Heavy & 322 & 501 & 50.4 & 75.1 & 0.22 & 0.12 & 0.24 & 0.40 \\
\hline & Light & 353 & 532 & 76.1 & 80.2 & 0.17 & 0.15 & 0.35 & 0.40 \\
\hline & Moderate & 238 & 463 & 30.9 & 69.9 & 0.34 & 0.15 & 0.29 & 0.30 \\
\hline & Heavy & 66 & 346 & 6.2 & 61.7 & 0.42 & 0.24 & 0.16 & 0.30 \\
\hline & Significance & $Q^{*}$ & $\mathrm{Q}^{* *}$ & $\mathrm{~L}^{*}$ & NS & $\mathrm{L}^{*}$ & $\mathrm{~L}^{*}$ & $\mathrm{~L}^{*}$ & $\mathrm{~L}^{*}$ \\
\hline
\end{tabular}

${ }^{\mathrm{z}} \mathrm{l}$ upright $/ \mathrm{ft}^{2}=10.7639$ uprights $/ \mathrm{m}^{2}, \mathrm{l} \mathrm{g} / \mathrm{ft}^{2}=0.0353 \mathrm{oz} / \mathrm{ft}^{2}=10.7639 \mathrm{~g} \cdot \mathrm{m}^{-2}$.

${ }^{y} \mathrm{Tau}=$ the ratio of below canopy light to above canopy light.

${ }^{x} U_{f}=$ number of reproductive uprights, $U_{t}=$ the total number of uprights.

"NS, * ${ }^{* *}$ are not significant and significant at $P=0.05$ and 0.01 , respectively, for linear $(\mathrm{L})$ and quadratic $(\mathrm{Q})$ effects

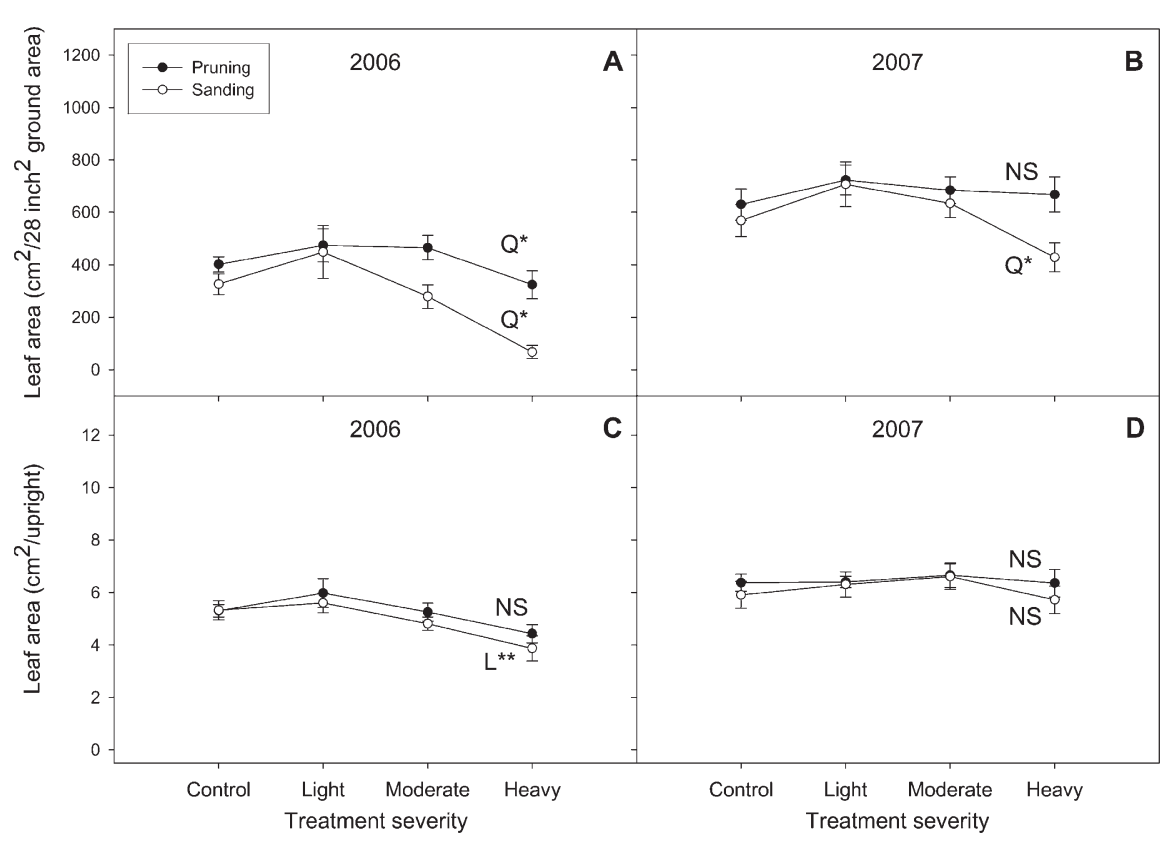

Fig. 1. Effect of various sanding and pruning treatments performed in Apr. 2006 on subsequent leaf area in 'Stevens' cranberry in (A) June 2006, (B) June 2007, and leaf area per upright in (C) June 2006, and (D) June 2007. Vertical bars are \pm SE ${ }^{\mathrm{NS}, ~}{ }^{*},{ }^{* *}$ Not significant, significant at $P=0.05, P=0.01$, respectively, for linear (L) and quadratic $(Q)$ effects; $1 \mathrm{~cm}^{2} / 28 \mathrm{inch}^{2}\left(180.6 \mathrm{~cm}^{2}\right)=0.5536 \mathrm{~mm}^{2} \cdot \mathrm{cm}^{-2}=$ $0.0055 \mathrm{inch}^{2} /$ inch $^{2}, 1 \mathrm{~cm}^{2}=0.1550 \mathrm{inch}^{2}$.

treatments on leaf area was due to decreased number of uprights. Decrease in leaf area indicates a potential negative effect on net photosynthetic activity from fruit set through harvest, a period when carbon production in cranberry is source limited (Vanden Heuvel and Davenport, 2005).

The ratio of $U_{f}: U_{t}$ in the year of treatment decreased linearly with increasing treatment severity for sanding and pruning (Table 1), similar to the results of Strik and Poole (1991). As more plant material is removed or buried with increasing severity, more reproductive and vegetative uprights are lost and $U_{t}$ decreases. When axillary buds are stimulated from sanding or pruning, these new uprights will be vegetative, causing a downward shift in the ratio of $U_{f}: U_{t}$. In the year after treatment, pruning severity did not affect the $\mathrm{U}_{\mathrm{f}}: \mathrm{U}_{\mathrm{t}}$ ratio, but the negative relationship between sanding severity and the $\mathrm{U}_{\mathrm{f}}: \mathrm{U}_{\mathrm{t}}$ ratio persisted.

Penetration of light and CHEMIGATION INTO THE CANOPY. Three months after treatment application (July 2006), light penetration into the canopy was greater in the sanding treatments than in the pruned plots and increased linearly with increasing severity in both (Table 1). Light interception by the uprights is important in July for flower bud initiation, a light-dependent process (Roper et al., 1993). The linear relationship between light penetration and treatment severity continued into late Aug. 2006 for sanding, but by that time, differences among pruning intensities were no longer evident (Table 1), suggesting that the canopy was quickly recovering. Light penetration to soil level in the second year was unaffected by treatment type or severity (Suhayda, 2008).

In July and August of the year of treatment (2006), pruning plots showed a linear increase with increasing severity for average number of dry hours per week [e.g., Aug. 2006: zero $=40 \pm 4.5 \mathrm{~h}$; light $=67 \pm 0.8 \mathrm{~h}$; moderate $=77 \pm 4.0 \mathrm{~h}$; and heavy $=$ $90 \pm 12.2$ h (see Suhayda, 2008)], suggesting a microclimate less favorable to fungal disease (Oudemans et al., 1998). There were no differences in dry hours among the sanding severities in the year of treatment or among any treatments in the year after treatment (2007). 
Chemigation of insecticides and fungicides is the most common application method for Massachusetts cranberry growers (J. Deverna, unpublished data). This conventional application method produced a spray that thoroughly penetrated the canopy in every plot and completely wetted the water-sensitive papers (data not shown). At this site, the spray reached all parts of the canopy regardless of treatment type or severity. Results may be different with a spray method that delivers a finer spray or lower volume or on a bed with a denser vine canopy. Good canopy penetration, regardless of pruning or sanding severity, has important ramifications for the efficacy and coverage of products that are chemigated for pest management purposes.

YIELD AND ANTHOCYANIN CONTENT. Severity trends for both practices were similar (Fig. 2, A-C); 2006, 2007 , and cumulative yields were greater for light severity treatments $(320 \pm 55.1,214.8 \pm 32.6$, and 535.5 $\pm 79.1 \mathrm{lb} /$ acre, respectively) than the moderate $(176.7 \pm 24.6,121.2 \pm$ 22.2 , and $297.9 \pm 43.9 \mathrm{lb} / \mathrm{acre}$, respectively) and heavy (142.7 \pm $26.9,107.1 \pm 24.7,249.8 \pm 47.4 \mathrm{lb} /$ acre, respectively) severity treatments $(P \leq 0.05)$. Yield differences between pruning and sanding were most apparent at the heavy severity, significant at $P \leq 0.06$ (2006: $176.7 \pm 20.5 \mathrm{lb} /$ acre vs. $108.8 \pm 46.9 \mathrm{lb} /$ acre; $2007: 153.8$ $\pm 29.2 \mathrm{lb} /$ acre vs. $60.4 \pm 23.0 \mathrm{lb} /$ acre; cumulative: $330.4 \pm 37.3 \mathrm{lb} /$ acre vs. $169.1 \pm 69.1 \mathrm{lb} /$ acre, respectively). The negative relationship between treatment severity and yield (Fig. 2, A-C) is similar to the results reported by Strik and Poole (1991, 1995) in Oregon. In a study of barge sanding in New Jersey (Davenport and Schiffhauer, 2000), yield reduction was associated with the application of $2.5 \mathrm{~cm}$ of sand (equivalent to the moderate treatment in this study). No treatment had an effect on average fruit weight or percentage of marketable yield (data not shown).

In the year of treatment, there was a significant positive linear relationship between pruning severity and anthocyanin concentration in the fruit (all values in milligrams per $100 \mathrm{~g}$ of fresh weight: zero $=30.6 \pm 2.10$; light $=$ $35.9 \pm 3.15$; moderate $=39.1 \pm 2.00$; and heavy $=39.9 \pm 1.08$; see Suhayda,

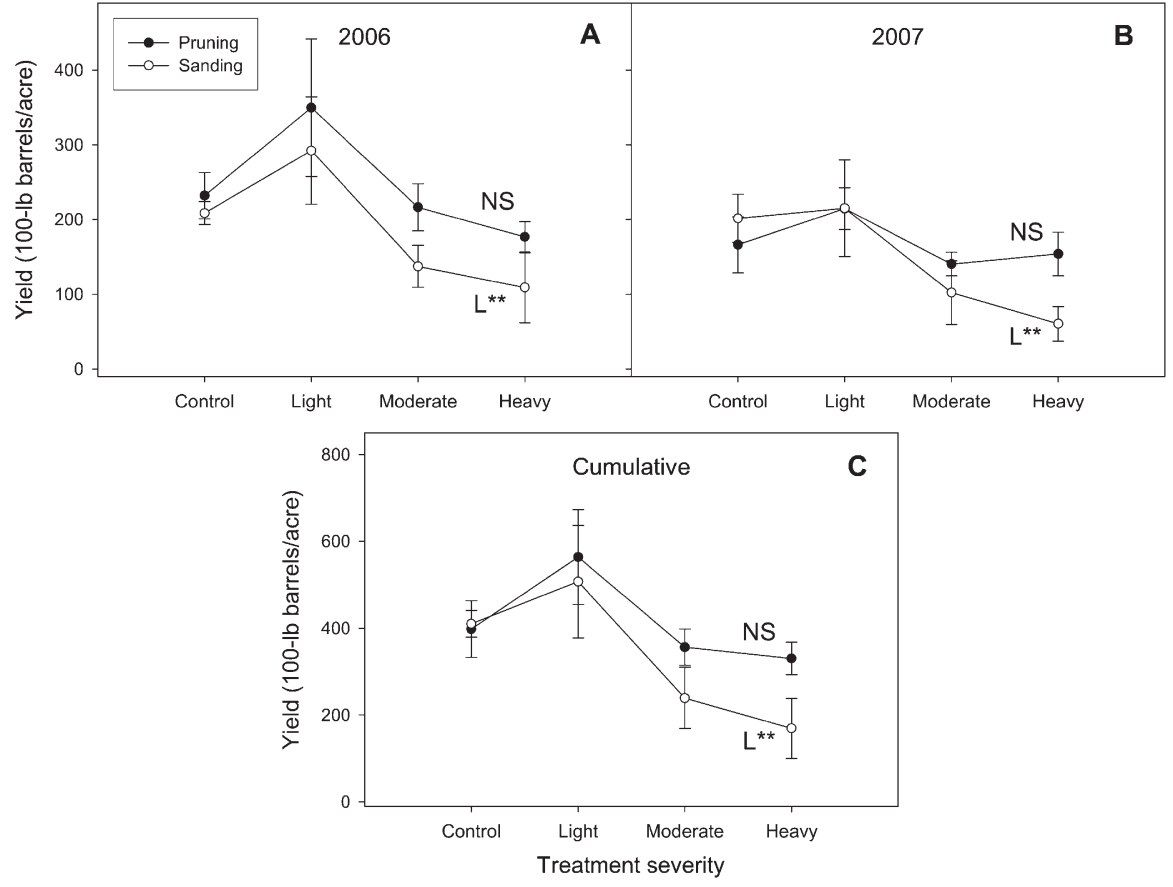

Fig. 2. Effect of various sanding and pruning treatments performed in Apr. 2006 on subsequent yield in 'Stevens' cranberry in (A) 2006, (B) 2007, and (C) 2-year cumulative yield. Vertical bars are $\pm \mathrm{SE}{ }^{\mathrm{NS},}{ }^{*},{ }^{*}$ Not significant and significant at $P=0.05$ and $P=0.01$, respectively, for linear (L) effects; $1100-1 b(45.4 \mathrm{~kg})$ barrel per acre $=112.0851 \mathrm{~kg} \cdot \mathrm{ha}^{-1}$.

2008), likely due to increased light penetration into the canopy with increasing pruning severity (Table 1 ) (Craker, 1971; Strik and Poole, 1991). However, while sanding treatments increased light penetration in the year of treatment even more than did pruning (Table 1), anthocyanin was not increased by sanding (Suhayda, 2008). It is possible that carbon limitations due to extreme leaf area decline in the sanded treatments (Fig. 1) prevented a response to increased light. Measurements from another study indicated that root growth is increased in the sanded layer and may account for additional resource partitioning away from leaf and fruit production (B. Lampinen and C. DeMoranville, unpublished data). In the year following treatment, there were no differences of sanding or pruning severity on fruit anthocyanin content among treatments or severities. This result is not unexpected because light penetration into the canopy had equilibrated across treatments in 2007 (i.e., no treatment effects; data not shown).

Economics. After accounting for the cost of the sanding or pruning and the production cost per acre, pruning severity did not affect net returns in the year of treatment, the year after, or on a cumulative basis for the 2 years (Table 2). This concurs with recent research on cranberry that examined four pruning severities with various nutritional regimens (Sandler and DeMoranville, 2009). Although deviation from these trends was not significant, it appears that light pruning gave the best returns.

For sanding, however, the relationship between severity and net returns was linear and negative. Net returns for growers who can mine sand on-farm would presumably be higher than those calculated here because the values used in this study included the cost of having screened sand delivered to the production area. While likely less than having sand delivered by a commercial company, the costs associated with using sand on-farm would still include labor to screen sand and move it to the production areas. These costs will vary from farm to farm depending on distance of the sand source to the production areas and the quality of the mined sand. Additionally, while the use of on-farm 
Table 2. Calculated yield, costs, and returns for 'Stevens' cranberry in the year of treatment and the year following. Calculations based on yield (Fig. 2) and cost data provided by cranberry growers (M. Beaton, R. Gilmore, and G. Rogers, personal communication).

\begin{tabular}{|c|c|c|c|c|c|c|c|c|c|}
\hline \multirow[b]{2}{*}{ Treatment } & \multirow[b]{2}{*}{ Severity } & \multirow{2}{*}{$\begin{array}{c}\text { Treatment } \\
\text { cost }(\$ / \text { acre })^{\mathrm{z}}\end{array}$} & \multicolumn{2}{|c|}{$\begin{array}{l}\text { Yield }(100-1 b \\
\text { barrel/acre })^{\mathrm{y}}\end{array}$} & \multicolumn{5}{|c|}{ Gross/net value ${ }^{\mathrm{x}}$ (\$/acre) } \\
\hline & & & 2006 & 2007 & 2006 gross & 2006 net & 2007 gross & 2007 net & 2-yr net \\
\hline \multirow{3}{*}{ Pruning } & Light & 179 & 349 & 215 & 13,592 & 10,213 & 9,309 & 6,009 & 16,222 \\
\hline & Moderate & 358 & 216 & 140 & 8,410 & 4,852 & 6,089 & 2,789 & 7,641 \\
\hline & Heavy & 537 & 177 & 154 & 6,870 & 3,133 & 6,675 & 3,375 & 6,508 \\
\hline \multirow{3}{*}{ Sanding } & Light & 1,291 & 292 & 215 & 11,363 & 6,872 & 9,335 & 6,035 & 12,907 \\
\hline & Moderate & 2,414 & 137 & 102 & 5,337 & -277 & 4,431 & 1,131 & 854 \\
\hline & Heavy & 3,535 & 109 & 60 & 4,232 & $-2,503$ & 2,621 & -679 & $-3,182$ \\
\hline
\end{tabular}

${ }^{\mathrm{z}}$ Cost of treatments based on values for equipment and labor costs provided by commercial cranberry growers and $\$ 12 /$ yard ${ }^{3}\left(\$ 15.70 / \mathrm{m}^{3}\right)$ sand; $\$ 1 /$ acre $=\$ 2.4711 / \mathrm{ha}$. y $100-\mathrm{lb}(45.4 \mathrm{~kg})$ barrel $/$ acre $=112.085 \mathrm{l} \mathrm{kg} \cdot \mathrm{ha}^{-1}$.

${ }^{\mathrm{x}}$ Gross values based on $\$ 38.50$ and $\$ 43.40$ per $100-\mathrm{lb}(45.4 \mathrm{~kg})$ barrel $(\$ 0.849 / \mathrm{kg}$ and $\$ 0.957 / \mathrm{kg}$, respectively) in 2006 and 2007 , respectively (U.S. Department of Agriculture, 2008); net value after initial treatment cost plus annual production cost for 2006 ( $\$ 3200 /$ acre) and net value after annual production cost ( $\$ 3300 /$ acre) for 2007 .

sand does not represent a cash outlay, the sand does have a value and is a finite resource.

\section{Conclusions}

Light pruning or sanding (a single pass with a knife-rake pruner or the application of $1.5 \mathrm{~cm}$ of sand, respectively) can be a useful tool for cranberry canopy management, as both practices can open up the canopy, resulting in decreased wetness duration and improved light interception. Light severity treatments appeared to have had a positive effect on yield and net returns compared with that in untreated controls. Light sanding and pruning were associated with increased leaf area compared with both untreated plots and those that received higher severity treatments. The increase in photosynthetic area likely translates into greater carbon resources for treated vines compared with those in the control plots. In addition, light sanding and pruning treatments had more uprights $\left(U_{t}\right)$ than the controls with a similar $U_{f}: U_{t}$ ratio and therefore had more $U_{f}$. The large number of reproductive uprights (i.e., more flowers), combined with an increase in carbon resources (i.e., increased potential for higher percentage fruit set), is the likely explanation for the apparent increase in yield seen with the light severity treatments.

Sanding is more risky than pruning due to its greater negative impact on yield when applications are heavy and because nonuniform application of sand (Hunsberger et al., 2006) may not provide the intended benefits Furthermore, sanding is more expensive than pruning, particularly if sand is purchased off-farm. On average, sanding plots had lower yield than pruning plots in the year of treatment. Heavy sanding treatments still had lower yields in the second year, whereas heavy pruning treatments were able to recover after the first year. This is an important consideration because the pest management benefits of sanding (e.g., suppression of cranberry girdler or dodder) are only effective with the equivalent of the moderate or heavy treatments used in this study (Franklin, 1951; Sandler et al., 1997). The prolonged decrease in yield associated with these severities may make sanding an unsustainable pest management option.

Because light severity sanding and pruning showed no negative effects in the year of treatment, either practice could be used annually as canopy conditions warrant. A previous study showed no negative impact of light annual pruning over a 4 -year period when combined with moderate nitrogen inputs (Sandler and DeMoranville, 2009), thus this cultural practice could be conducted frequently. Based on the recovery data from the present study, the interval between sanding events should be at least 3 years if greater than $1.5 \mathrm{~cm}$ of sand is applied. Due to the potential benefits of light pruning and the reduced risk of overtreatment compared with sanding, pruning may be a viable option for cranberry growers as a replacement for or as a supplement to sanding for canopy management.

\section{Literature cited}

Chambers, F.S. 1918. Cranberry pruning experiments. Proc. 48th Annu. Mtg. Amer. Cranberry Growers' Assn. p. 3-7.

Craker, L.E. 1971. Postharvest color promotion in cranberry with ethylene. HortScience 6:137-139.

Davenport, J.R. and D.E. Schiffhauer. 2000. Cultivar influences cranberry response to surface sanding. HortScience 35:53-54.

Davenport, J.R. and N. Vorsa. 1999. Cultivar fruiting and vegetative response to nitrogen fertilizer in cranberry. J. Amer. Soc. Hort. Sci. 124:90-93.

DeMoranville, C.J. 2009. Nutrition management for producing bogs, p. 42-52. In: M.M. Sylvia and N. Guerin (eds.). Cranberry chart book: Management guide for Massachusetts. I July 2009. <http://www.umass.edu/cranberry/ downloads/chartbooks/2009/ Nutrition2009.pdf>.

DeMoranville, C.J. and H. Sandler. 2000. Best management practices guide: Sanding. 3 Sept. 2008. <http://www.umass. edu/cranberry/services/bmp/sanding. shtml>.

Eck, P. 1990. The american cranberry. Rutgers Univ. Press, New Brunswick, NJ.

Franklin, H.J. 1951. Cranberry insects in Massachusetts, Parts II-VII. Massachusetts Agr. Expt. Sta., East Wareham, MA.

Fuleki, T. and F.J. Francis. 1968. Quantitative methods for anthocyanins. 1 . Extraction and determination of total 
anthocyanin in cranberries. J. Food Sci. 33:72-77.

Hunsberger, L.K., C.J. DeMoranville, W.R. Autio, and H.A. Sandler. 2006. Uniformity of sand deposition on cranberry bogs and implications for swamp dodder control. HortTechnology 16:488492.

Lampinen, B.D. and C.J. DeMoranville. 2003. Effect of irrigation and sand application on cranberry growth and yield. HortScience 38:493. (Abstr.).

Marucci, P.E. 1987. A rationale for the pruning of cranberries. Cranberries $51(4)$ : 3-10.

Oudemans, P.V., F.L. Caruso, and A.W. Stretch. 1998. Cranberry fruit rot in the northeast: A complex disease. Plant Dis. 82:1176-1184.

Roper, T.R. and N. Vorsa. 1997. Cranberry: Botany and horticulture. Hort. Rev. (Amer. Soc. Hort. Sci.) 21:215-249.

Roper, T.R., J. Klueh, and M. Hagidimitriou. 1995. Shading timing and intensity influences fruit set and yield in cranberry. HortScience 30:525-527.

Roper, T.R., K.D. Patten, C.J. DeMoranville, J.R. Davenport, B.C. Strik, and A.P. Poole. 1993. Fruiting of cranberry uprights reduces fruiting the following year. HortScience 28:228.

Sandler, H.A. and C.J. DeMoranville. 2009. Economic analysis of nitrogen rate on vine production and fruit yield of pruned cranberry beds. HortTechnology 19:572-579.

Sandler, H.A., M.J. Else, and M. Sutherland. 1997. Application of sand for inhibition of swamp dodder (Cuscuta gronovii) seedling emergence and survival on cranberry ( Vaccinium macrocarpon) bogs. Weed Technol. 11:318-323.

Strik, B.C. and A. Poole. 1991. Timing and severity of pruning effects on cranberry yield components and fruit anthocyanin. HortScience 26:1462-1464.

Strik, B.C. and A. Poole. 1992. Alternateyear pruning recommended for cranberry. HortScience 26:1327.
Strik, B.C. and A. Poole. 1995. Does sand application to soil surface benefit cranberry production? HortScience 30:47-49.

Suhayda, B. 2008. The effect of sanding and pruning on yield and canopy microclimate in 'Stevens' cranberry. Dept. Plant, Soil, and Insect Sciences. Univ. Massachusetts, Amherst, Masters thesis.

Toledo, J.U., M.A.L. Smith, and L.A. Spomer. 1993. Light influence on in vitro anthocyanin production in three cranberry (Vaccinium macrocarpon) cultivars. HortScience 28:447. (Abstr.).

U.S. Department of Agriculture. 2008. Massachusetts and Maine cranberries. 25 Jan. 2008. 15 May 2008. <http:// www.nass.usda.gov/Statistics_by_State/ New_England_includes/Publications / jancran.pdf $>$.

Vanden Heuvel, J.E. and J.R. Davenport. 2005. Effects of light, temperature, defoliation, and fruiting on carbon assimilation and partitioning in potted cranberry. HortScience 40:1699-1704. 